\section{RevistadePolítica Económica y Desarrollo Sostenible}

Centro Internacional de Política Económica para el Desarrollo Sostenible
Revista de Política Económica y Desarrollo Sostenible

EISSN: 2215-4167 • Vol. 4 (1) • Julio-Diciembre, 2018: 1-17

DOI: http://dx.doi.org/10.15359/peds.4-1.3

URL: http://www.revistas.una.ac.cr/politicaeconomica

Revista electrónica semestral publicada por el Centro Internacional de Política Económica para el Desarrollo Sostenible

Universidad Nacional, Lagunilla, Heredia Apartado 2393-3000

\title{
Caficultores replanteando su participación en la cadena del café: casos de Costa Rica y México
}

\section{Coffee Producers Rethinking Their Participation in The Coffee Chain: Cases of Mexico and Costa Rica}

\author{
Alejandro Luna-González ${ }^{1}$, \\ Rafael A. Díaz-Porras, \\ Victorino Morales-Ramos ${ }^{3}$, \\ Yesica Mayett-Moreno ${ }^{4}$ \\ rafael.diaz.porras@una.ac.cr
}

Fecha de recibo: 16 de agosto del 2018. Fecha de corrección: 24 de octubre del 2018.

Fecha de aceptación: 29 de octubre del 2018. Fecha de publicación: 2 de noviembre del 2018

\section{Resumen}

El principal mercado para países productores de café es el extranjero, bajo esquemas de comercialización organizados por un grupo de compradores. Esto obliga a países productores como México y Costa Rica a desarrollar cambios en la forma en que participan en las cadenas de valor, donde la calidad del café es determinante para tratar de negociar un mejor precio al productor. El objetivo del presente estudio fue analizar comparativamente las estrategias de valor agregado, considerando el uso de certificaciones y procesos de gestión de calidad en ambos países. Se utilizó el enfoque de cadenas globales de valor para analizar la estrategia de los productores que realizan la transformación (llamados beneficiados/Beneficios). La información se recopiló de 64 Beneficios (Molinos) de café: 67.1 \% en Costa Rica y 32.9 \% en México. En Costa Rica se encontró que existe una correlación entre contar con certificaciones y la capacidad instalada (Pearson de .457 significativa a $\mathrm{P}<.05$ ). En el caso de México se encontró una correlación entre contar con certificaciones y obtener mejores ingresos (Pearson de .693 significativa a $\mathrm{P}<.05)$. La estrategia de certificación del café costarricense es útil para acceder a canales de comercialización en venta por volumen y, en el caso de México, además asegura el precio de venta. La estrategia de selección de café en grano en el Beneficio es clave para incrementar la calidad en taza, innovando en diferentes productos especializados y comercializarlo tanto en mercados tradicionales como nuevos mercados. Implementar la estrategia de gestión de calidad posibilita un mayor grado de integración en la cadena.

Palabras clave: Beneficios, calidad, certificaciones, exportadores, selección.

\footnotetext{
Colegio de Postgraduados, Campus Puebla, Boulevard Forjadores de Puebla 205, Santiago Momoxpan, San Pedro Cholula 72760, Puebla, México. Centro Internacional de Política Económica para el Desarrollo Sostenible. Universidad Nacional de Costa Rica. Lagunilla, Heredia, Costa Rica. Colegio de Postgraduados, Campus Córdoba, km 348 Carretera Federal Córdoba-Veracruz, Congregación Manuel León, Amatlán de los Reyes 94946, Veracruz, México.

4 Universidad Popular Autónoma del Estado de Puebla. Calle 17 sur 901, Barrio de Santiago 72410, Puebla, México.
} 


\begin{abstract}
The main market for coffee producers' countries are abroad, particularly when such markets are under the control of few international companies who buy de product. This lead some countries like Mexico and Costa Rica to develop changes in the way they participate in value chain, where the quality of the coffee is decisive at the moment of negotiating a better price for the producer. The main objective of this research was to compare the value-added strategies in both countries, based on certification's adoption and a quality management processes. We did use the global value chain approach to analyze the producer's strategy who transform or process the coffee 11 in "Beneficiaries" or mills). The information was obtained from 64 Coffee mills, $67.1 \%$ in Costa Rica and 32.9\% in Mexico. We found that in the case of Costa Rica there is a Pearson correlation of .457 (significant at $\mathrm{P}<.05$ ), between having certifications and installed capacity. In Mexico's case, the Pearson correlation was of 693 (significant at $\mathrm{P}<.05$ ), between having certifications and obtaining better income. The coffee certification is a very commonly used strategy, to access to sales channels by volume in Costa Rica, while in Mexico a price strategy is more frequent. The coffee selection in the mill is a main issue to increase the quality of the coffee, allowing innovation in different specialized products and commercializing them in both traditional markets and new markets. The adoption of a quality management strategy would enable the integration in the coffee chain.
\end{abstract}

Keywords: Mills, quality, certifications, exports, selection.

\title{
Introducción
}

Las cadenas globales de mercancías (CGM) son, en gran medida, resultado de la globalización y han propiciado el desarrollo económico de muchas industrias hacia la exportación. El café es uno de los productos con los que se puede ejemplificar dicha tendencia, debido a que vincula a los productores que realizan las actividades cafetaleras en países subdesarrollados con los consumidores de países desarrollados (Pérez y Echánove, 2006).

Para el análisis de las CGM, se tienen cuatro dimensiones básicas: a) la estructura insumoproducto de creación de valor agregado; b) la dimensión espacial de las actividades productivas; c) el contexto institucional y sociopolítico; y d) cada cadena tiene una estructura o fuerza de control (Pelupessy, 2001).

La primera dimensión en la CGM estructura insumo-producto, en el café se refiere a las actividades que se realizan desde el cultivo hasta el producto que se entrega al consumidor final en taza. Esta se segmenta en varias etapas, en donde los diferentes actores que actúan en esta cadena generan un valor agregado al producto.

La segunda dimensión se enfoca en los diversos países que interactúan como actores productores de café y los países consumidores, debido a que los segmentos en los que se divide la cadena se encuentran en diferentes ubicaciones geográficas en el mundo.

La tercera dimensión hace referencia a las instituciones que interactúan con el sector y crean o regulan las legislaciones que determinan cómo funciona, se produce y comercializa el 
café. Para el caso de Costa Rica esta institucionalidad gira en torno al Instituto del Café (ICAFE), fundado desde 1933 (ICAFE, 2018) y, para el caso de México, esta función la asumía el Instituto Mexicano del Café hasta 1989, después la ocupó el Consejo Mexicano del Café, que se encargó hasta el 2005 de la política económica del sector cafetalero, y actualmente lo realiza el Sistema Producto Café (Pérez y Echánove, 2006).

La cuarta dimensión hace referencia a cómo y quién organiza la cadena. El caso del café presenta un sistema de control global desde el comprador (categoría definida por Gerefi, 2001). Sin embargo, entre los segmentos de producción se tiene que la cadena no es integrada en forma vertical, sino que son empresas independientes pero interconectadas que forman redes de producción global, donde las empresas que están estratégicamente ubicadas en el centro controlan los flujos de información y los recursos.

Es importante señalar que se refiere al término de comprador, para fines de este artículo, como todas aquellas empresas transformadores de café verde en café tostado, ya sean nacionales o extranjeras, que pueden estar ubicadas en los eslabones de Beneficio, torrefacción o exportación, no se refiere al consumidor final. En cuanto al término Beneficio, se utilizará en mayúscula debido a que hace referencia al segundo eslabón de la cadena como actor, pues es quien desarrolla los procesos de transformación de café cereza a café verde, ya sea mediante el método húmedo o seco, y no se refiere a la ganancia financiera o al sinónimo de bienestar social.

Como países productores, tanto Costa Rica como México buscan estrategias de agregación de valor en la primera dimensión de la cadena, donde pueden incidir al ser países productores. La cadena de valor abarca las actividades del cultivo, recolección, despulpado, tratamiento, secado, cribado, distribución, almacenamiento, comercialización, trillado, clasificado y empaque (García y Olaya, 2006).

En el caso de Costa Rica, la primera dimensión está bien definida y delimitada en eslabones por el ICAFE desde 1961 (ICAFE, 2018). La primera dimensión está ocupada por los productores y beneficiadores, que son el primer y segundo eslabón de la cadena. La segunda dimensión está ocupada por los exportadores y la tercera dimensión, por los torrefactores. Sin embargo, a diferencia de Costa Rica, la cadena de café en México no está delimitada legalmente: la primera dimensión insumo-producto puede ser realizada desde el eslabón de productor, comercializador y tostador, quienes además forman parte de la estructura que regula los flujos en la cadena (Pérez y Echánove, 2005).

Para poder integrarse al mercado mundial, los productores y beneficiadores deben realizar algún proceso adicional a estas actividades o bien diferenciar sus productos para poder ganar participación en el mercado (Castillo, 2001). Esto se puede lograr mediante la estrategia de agregación de valor a través de las certificaciones y la gestión de la calidad, cuidando la selección del café (Montoya y Montoya, 2015).

La selección del café se refiere a los métodos que se utilizan para separar los defectos físicos del grano desde café cereza hasta café verde, por métodos manuales o mecánicos, desde la selección en cosecha, por flotes, chancador repasador o despulpadora horizontal, por tamaños 
en cribas, por densidad, por color, por catación. Esta selección se hace de acuerdo con los requerimientos de calidad de cada país o del comprador, pero existen estándares internacionales como los SCAA (Specialty Coffee Association of America, 2018), que definen el número de defectos que puede tener el café y el color, en los cuales se basan los compradores.

El objetivo de este estudio fue analizar comparativamente las estrategias de valor agregado desarrolladas por organizaciones de productores, considerando el uso de certificaciones disponibles en cada país y la aplicación de procesos de gestión de la calidad en ambos países. El poder identificar los puntos clave de estas dos estrategias será de utilidad a los Beneficiadores y comercializadores de ambos países para saber hacia dónde enfocar sus esfuerzos y poder avanzar en la cadena de valor del café.

\section{Metodología}

El enfoque de cadenas propuesto por Gereffi utiliza el análisis histórico para entender el contexto en el que se desarrollan las cadenas y cómo se pueden hacer escalonamientos en la cadena (traducido como upgrading). Este es el enfoque que aplicaremos en el caso del café como la han utilizado también diversos autores (Pérez y Echánove, 2006; García y Olaya, 2006; Peters, 2004; Kosacoff y López, 2008).

La definición de cadena de valor puede usarse como una herramienta para el análisis al interior de la empresa en la búsqueda de mejorar las actividades que se realizan. La diferencia con la globalización es que dichas actividades ahora se realizan en diversos puntos geográficos y no solo al interior de la empresa (Porter, 1990). Esta dispersión global de las cadenas productivas brinda la oportunidad para que los países en desarrollo participen en el comercio, teniendo la posibilidad de especializarse en las etapas del trabajo intensivo en el proceso de fabricación de un producto (Gereffi, 2001).

Las cadenas globales de valor están basadas en el establecimiento de amplias redes de trabajo generadoras de valor agregado. La inserción exitosa en las cadenas dependerá en gran medida de la ubicación que tengan dichas empresas globalmente, ya que esta será la que determine los beneficios obtenidos mediante la vinculación con las mismas. De esta forma, la competitividad de un país se refiere a la capacidad para participar, mantenerse y escalar en las cadenas globales (Cattaneo et al., 2013). Para realizar dichos escalamientos es necesario realizar estrategias de agregación de valor al producto a través de la gestión de calidad, diferenciándolo en los distintos eslabones de la cadena y adquiriendo capacidades (Jaramillo y Riveros, 2013).

Los sujetos de estudio fueron dueños o socios, gerentes o jefes de producción encargados o jefes de certificación y calidad, y otros puestos administrativos de Beneficios ubicados en estados o regiones productoras de café, seleccionados por el lugar de importancia que ocupan. En Costa Rica, el número total de Beneficios es de 49, que representa el $20 \%$ del total de aquellos inscritos en la guía de café de Costa Rica (ICAFE, 2017), y se ubican en la zona de Valle Occidental,. En México, se consultó el $23.6 \%$ del total de los Beneficios inscritos en el Directorio de beneficiadoras, centros de acopio e industrializadoras de café de México (SENASICA, 2018). 
Se diseñó una encuesta semiestructurada, sin ocultamiento y con método de administración cara a cara, que mide cualitativamente el impacto de las estrategias de agregación de valor a través de certificaciones y gestión de calidad en la transformación del café (procesos de beneficiado húmedo y seco), en las áreas económica, organizacional, ambiental y comercial. En la presente investigación se analizaron dos estrategias de agregación de valor: las certificaciones y la gestión de calidad a través de procesos de selección en los Beneficios.

La primera mitad de la encuesta analiza el efecto que tienen las certificaciones en los Beneficios de café como estrategia de agregación de valor, buscando identificar si generan un impacto económico, comercial, ambiental y si propician el enlace a los eslabones en la cadena; además de analizar cuál es la certificación más difícil de obtener y el grado de especialización que se requiere, así como también la relación costo-utilidad. Es a través de las certificaciones que se establecen parámetros en los países productores de café que verifican sus sistemas e impactos hacia la sostenibilidad económica, ambiental y social (Álvarez, 2008).

La segunda estrategia que se analiza en la parte dos de la encuesta es el proceso de gestión de calidad que se realiza desde la cosecha a través de la selección de café (Puerta, 2000a; Marín et al., 2003), la selección en el beneficio húmedo (Oliveros et al., 2010) y la selección y la importancia de la secuencia de selección en el proceso del beneficio seco (Soto y Jiménez, 1995), nuevamente midiendo si generan un impacto económico, comercial, ambiental y cómo se relaciona con los eslabones en la cadena. Por último se pregunta sobre aquella selección que requiere mayor especialización en la operación y la relación costo-utilidad.

La gestión de calidad que conforma el proceso de selección de café identificada en ambos países es la siguiente: selección en cosecha, selección por flotes, despulpador de cilindro horizontal, densimétrica, por tamaño en zaranda, electrónica por color, catación, selección manual y granulométrica.

Para determinar si existe relación entre la integración en la cadena y la gestión de calidad, se desarrolló un índice con base en la ponderación. El índice de integración en la cadena se ponderó calificando cada Beneficio con 1 en caso de que estuvieran integrados y 0 en el caso contrario, sumando los resultados de la participación de los Beneficios en cada eslabón de la cadena y dividiéndolo entre el total de los Beneficios entrevistados. De esta manera, se obtuvo un porcentaje que asigna la importancia de cada eslabón, multiplicando cada uno de estos porcentajes por 1 o 0 , según fuera el caso, si estaba integrado o no el Beneficio entrevistado en este eslabón, y sumando los resultados de todos los eslabones para cada Beneficio.

El índice de gestión de calidad se ponderó calificando a cada Beneficio con 1 en caso de que aplicaran el método de selección y 0 en el caso contrario, sumando los resultados de los Beneficios que aplicaban el método y dividiéndolo entre el total de los Beneficios entrevistados. Así, se obtuvo un porcentaje que asigna la importancia de cada método, multiplicando cada uno de estos porcentajes por 1 o 0 , según fuera el caso, si el Beneficio aplicaba el método de selección o no, y sumando los resultados de todos los métodos aplicados por cada Beneficio.

Mediante el programa IBM SPSS Statistics 19 (International Business Machines, 2010) se capturaron los resultados de las encuestas y fueron aplicados análisis de estadística descriptiva, tanto de frecuencias como tablas de contingencia. 
Revista de Política Económica • EISSN: 2215-4167

Vol. 4 (1) • Julio-Diciembre, 2018: 1-17

Alejandro Luna-González

Rafael A. Díaz-Porras

DOI: http://dx.doi.org/10.15359/peds.4-1.3

Victorino Morales-Ramos

URL: http://www.revistas.una.ac.cr/politicaeconomica

Yesica Mayett-Moreno

\section{Resultados}

De los Beneficios entrevistados en Costa Rica, 5 ya no están en funciones y solo 1 decidió no participar, por lo que se obtuvo un total de 43 encuestas de los Beneficios que participaron, respondidas por dueños o socios (49\%), gerentes o jefes de producción (21\%), encargados o jefes de certificación y calidad (7 \%), y otros puestos administrativos (23\%). De los Beneficios entrevistados en México, 2 ya no están en funciones y 3 decidieron no participar, por lo que se logró encuestar 21 Beneficios y las encuestas fueron respondidas por gerentes o jefes de producción (38\%), encargados o jefes de certificación y calidad (33\%), dueños y socios (14 \%), y recursos humanos $\mathrm{u}$ otros puestos administrativos el $15 \%$ restante.

Los Beneficios en México, respecto de Costa Rica, son más antiguos: el $52 \%$ de ellos tiene 22 años o más y posee una mayor capacidad instalada de 163,789 toneladas o más por ciclo productivo, que representa el $31 \%$ de ellos, por lo que procesan el café de más productores en menos Beneficios. La catación del café es importante para ambos países, sin embargo, para Costa Rica la puntuación es más alta en el puntaje en taza: un punto más en el rango máximo y tres puntos arriba en el rango mínimo, a pesar de que la mayor parte del café que beneficia es convencional, es decir, es café que no cuenta con certificado orgánico (cuadro 1).

Cuadro 1.

Perfil de los Beneficios de café encuestados en Costa Rica y México

\begin{tabular}{|c|c|c|c|c|c|c|}
\hline Clasificación & País & Moda & $\begin{array}{l}\text { Media } \\
\text { aritmética }\end{array}$ & $\begin{array}{l}\text { Porcentaje que } \\
\text { representa del total }\end{array}$ & $\begin{array}{l}\text { Rango } \\
\text { mínimo* }\end{array}$ & $\begin{array}{l}\text { Rango } \\
\text { máximo* }\end{array}$ \\
\hline \multirow{2}{*}{$\begin{array}{l}\text { Tipo de } \\
\text { organización }\end{array}$} & Costa Rica & Asociación & - & 62.8 & - & - \\
\hline & México & Asociación & - & 95.2 & - & - \\
\hline \multirow[t]{2}{*}{ Antigüedad en años } & Costa Rica & - & 19 & 23.3 & 1 & 197 \\
\hline & México & - & 22 & 52.6 & 5 & 39 \\
\hline \multirow{2}{*}{$\begin{array}{l}\text { Capacidad instalada } \\
\text { qq por ciclo }\end{array}$} & Costa Rica & - & 17,673 & 16.3 & 100 & 150,000 \\
\hline & México & - & 163,789 & 31.6 & 400 & 700,000 \\
\hline \multirow{2}{*}{$\begin{array}{l}\text { Número de } \\
\text { productores }\end{array}$} & Costa Rica & - & 414 & 16.3 & 1 & 4,000 \\
\hline & México & - & 1,312 & 26.3 & 1 & 5,000 \\
\hline \multirow{2}{*}{$\begin{array}{l}\text { Número de } \\
\text { Beneficios }\end{array}$} & Costa Rica & 1 & - & 95.3 & 1 & 3 \\
\hline & México & 1 & - & 52.4 & 1 & 5 \\
\hline \multirow[t]{2}{*}{ Realizan catación } & Costa Rica & Sí & - & 95.3 & - & - \\
\hline & México & Sí & - & 95.2 & - & - \\
\hline \multirow[t]{2}{*}{ Puntuación en taza } & Costa Rica & 85 & 86 & 27.9 & 82 & 91 \\
\hline & México & 84 & 84 & 33.3 & 79 & 90 \\
\hline \multirow{2}{*}{$\begin{array}{l}\text { Tipo de café que se } \\
\text { beneficia }\end{array}$} & Costa Rica & Convencional & - & 58.1 & - & - \\
\hline & México & Mixto & - & 52.4 & - & - \\
\hline \multirow{2}{*}{$\begin{array}{l}\text { Variedad de café } \\
\text { que se beneficia }\end{array}$} & Costa Rica & Caturra & - & 83.7 & - & - \\
\hline & México & Costa Rica 95 & - & 81 & - & - \\
\hline
\end{tabular}

${ }^{*}$ Solo es aplicado en valores numéricos.

$\mathrm{Qq}=$ quintales

Fuente: Elaboración propia. 
La Figura 1 muestra cómo están integrados en los diferentes eslabones de la cadena los Beneficios, tanto de Costa Rica como de México. En Costa Rica, el $33 \%$ de los Beneficios está exportando su café de forma directa y el $65 \%$ indirectamente, mientras que en México el $67 \%$ de los Beneficios exportan su café de manera directa y el $14 \%$ indirectamente. A pesar de realizar más beneficios la exportación directa en México, el total de los beneficios que exporta es menor del 81 \% frente al 98 \% de Costa Rica. En México existe un 30 \% más de Beneficios integrados en el eslabón de torrefacción frente a Costa Rica, debido a la falta de exportación, por lo que tienen que tostar el café y vender el al mercado local (figura 1).

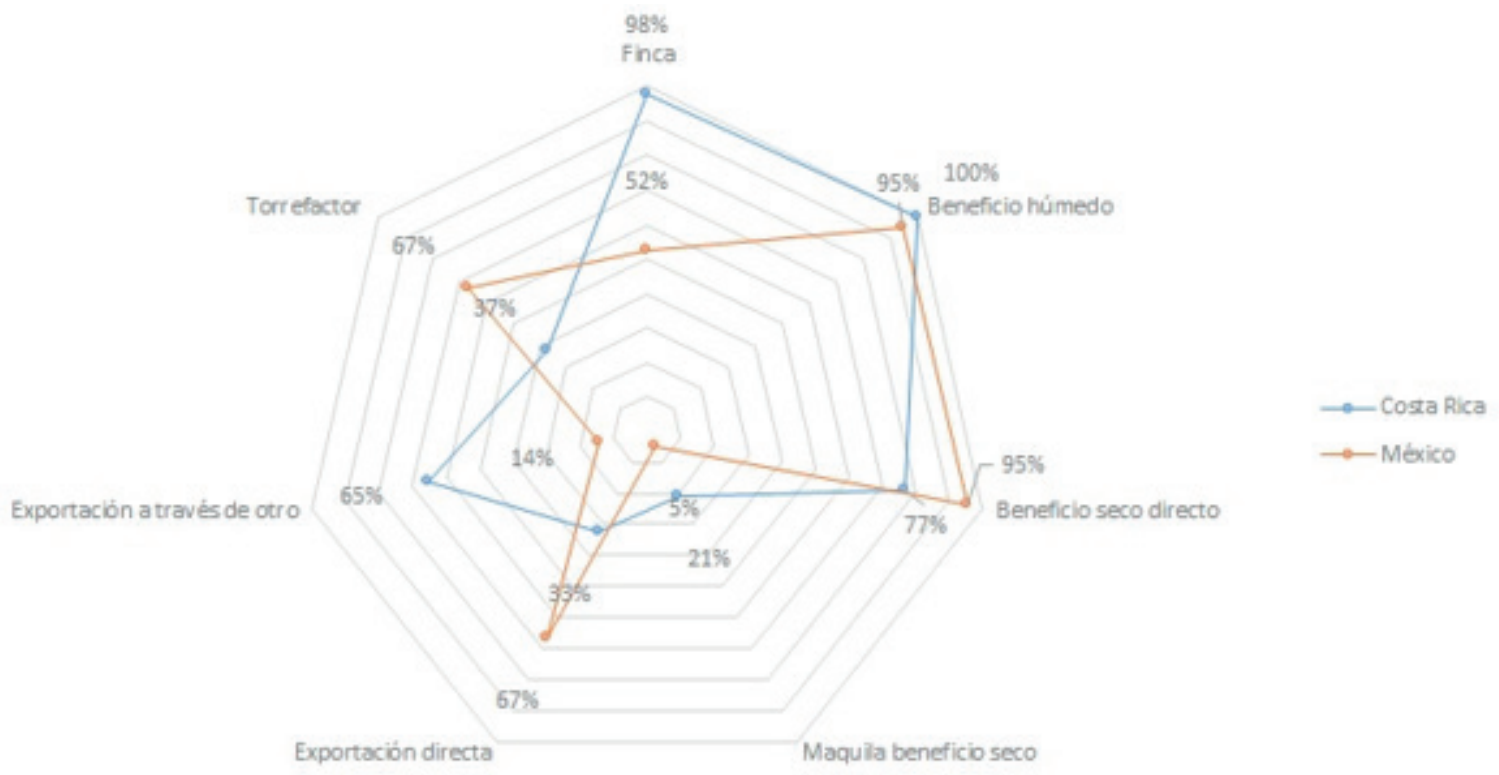

Figura 1. Integración de los beneficios de café en los eslabones de la cadena

Las certificaciones que de acuerdo a ambos países se identificaron y midieron en la encuesta fueron, para Costa Rica: Rainforest Alliance, Nespresso AAA, Buenas Prácticas Agrícolas, Fair Trade, Marca País, Orgánico, Woman Care, Certificado UTZ, ISO 9001, ISO 14001, C.A.F.E. Practice, Asociacion de Cafés Finos y Carbono Neutro. Para México: Rainforest Alliance, Nespresso AAA, Fair Trade, Orgánico, Certificado UTZ, ISO 9001, ISO 14001, ISO 22000, C.A.F.E. Practice, Kosher, Safety Quality Food y 4C.

El Cuadro 2 presenta la estrategia de valor agregado a través de las certificaciones, solo presenta la respuesta estadística y la razón más significativa. En Costa Rica, las certificaciones solo les son útiles para comercializar el café a ciertos mercados y verificar el cuidado del 
Revista de Política Económica • EISSN: 2215-4167

Vol. 4 (1) • Julio-Diciembre, 2018: 1-17

Alejandro Luna-González

Rafael A. Díaz-Porras

DOI: http://dx.doi.org/10.15359/peds.4-1.3

Victorino Morales-Ramos

URL: http://www.revistas.una.ac.cr/politicaeconomica

Yesica Mayett-Moreno

ambiente, en comparación con México donde dichas certificaciones les brindan más utilidades sobre el costo y les garantizan un precio. De acuerdo con la opinión de los entrevistados en los Beneficios, en México la calidad en taza se verifica a través de certificaciones y en Costa Rica la calidad en taza ya no depende de las certificaciones para ser validada.

Cuadro 2.

Análisis de la estrategia de certificación entre Costa Rica y México

\begin{tabular}{|c|c|c|c|c|c|c|}
\hline Preguntas & Costa Rica & Porcentaje & ¿Por qué razón? & México & Porcentaje & ¿Por qué razón? \\
\hline ¿Están certificados? & No & 58.1 & No les interesa & Sí & 66.7 & $\begin{array}{l}\text { Les da un mejor } \\
\text { precio }\end{array}$ \\
\hline $\begin{array}{l}\text { Certificación más } \\
\text { encontrada }\end{array}$ & $\begin{array}{l}\text { Rainforest } \\
\text { Alliance }\end{array}$ & 25.6 & Lo pide su mercado & $\begin{array}{l}\text { Rainforest } \\
\text { Alliance }\end{array}$ & 38.1 & $\begin{array}{l}\text { Lo pide su mer- } \\
\text { cado }\end{array}$ \\
\hline $\begin{array}{l}\text { ¿Qué certificación } \\
\text { es más difícil de } \\
\text { obtener? }\end{array}$ & Ninguna & 35.7 & $\begin{array}{l}\text { Con buenas prácticas } \\
\text { es fácil obtenerla }\end{array}$ & $\begin{array}{l}\text { Rainforest } \\
\text { Alliance }\end{array}$ & 23.8 & $\begin{array}{l}\text { Es exigente en sus } \\
\text { requerimientos }\end{array}$ \\
\hline $\begin{array}{l}\text { ¿Cuál requiere } \\
\text { mayor grado de } \\
\text { especialización? }\end{array}$ & Ninguna & 19.0 & $\begin{array}{l}\text { Si cumples con los } \\
\text { requisitos mínimos }\end{array}$ & $\begin{array}{l}\text { Rainforest } \\
\text { Alliance }\end{array}$ & 23.8 & Cuida cada detalle \\
\hline $\begin{array}{l}\text { ¿Cuál facilita la } \\
\text { comercialización? }\end{array}$ & $\begin{array}{l}\text { Rainforest } \\
\text { Alliance }\end{array}$ & 16.7 & $\begin{array}{l}\text { Acceso y preferencia a } \\
\text { más mercados }\end{array}$ & Orgánico & 28.6 & $\begin{array}{l}\text { Va hacia un merca- } \\
\text { do Europeo }\end{array}$ \\
\hline $\begin{array}{l}\text { ¿Cuál genera } \\
\text { encadenamientos } \\
\text { productivos? }\end{array}$ & $\begin{array}{l}\text { Todas son } \\
\text { iguales }\end{array}$ & 14.3 & $\begin{array}{l}\text { Trabajan con toda la } \\
\text { cadena }\end{array}$ & $\begin{array}{l}\text { Todas son } \\
\text { iguales }\end{array}$ & 19.0 & $\begin{array}{l}\text { Eso buscan a dife- } \\
\text { rente profundidad }\end{array}$ \\
\hline $\begin{array}{l}\text { ¿Cuál otorga } \\
\text { mejores ingresos a } \\
\text { productores? }\end{array}$ & Ninguna & 19.0 & $\begin{array}{l}\text { No brindan mejores } \\
\text { ingresos }\end{array}$ & Fair Trade & 28.6 & $\begin{array}{l}\text { Asegura un precio } \\
\text { y lo aumenta si es } \\
\text { orgánico }\end{array}$ \\
\hline $\begin{array}{l}\text { ¿Cuál cuida el } \\
\text { medio ambiente? }\end{array}$ & $\begin{array}{l}\text { Rainforest } \\
\text { Alliance }\end{array}$ & 23.8 & $\begin{array}{l}\text { Es estricta en las prác- } \\
\text { ticas que pide }\end{array}$ & Orgánico & 33.3 & Se enfoca en eso \\
\hline $\begin{array}{l}\text { ¿Qué otros aspectos } \\
\text { aporta? }\end{array}$ & Ninguno & 46.5 & No les aporta nada & $\begin{array}{l}\text { Desarrollo } \\
\text { Social }\end{array}$ & 38.1 & $\begin{array}{l}\text { Apoya a los pro- } \\
\text { ductores }\end{array}$ \\
\hline $\begin{array}{l}\text { ¿Cuál mejora la } \\
\text { calidad en taza? }\end{array}$ & $\begin{array}{l}\text { No tiene } \\
\text { relación }\end{array}$ & 78.6 & $\begin{array}{l}\text { Puedes tener buena } \\
\text { calidad sin ella }\end{array}$ & $\begin{array}{l}\text { Nespresso } \\
\text { AAA }\end{array}$ & 19.0 & $\begin{array}{l}\text { Cuidan el proceso } \\
\text { para tener la mejor } \\
\text { taza }\end{array}$ \\
\hline $\begin{array}{l}\text { ¿Cuál es la relación } \\
\text { costo-utilidad? }\end{array}$ & $\begin{array}{l}\text { No genera } \\
\text { utilidades }\end{array}$ & 27.9 & $\begin{array}{c}\text { No se justifica respecto } \\
\text { el costo }\end{array}$ & $\begin{array}{l}\text { Son más los } \\
\text { utilidades }\end{array}$ & 33.3 & Respecto al costo \\
\hline $\begin{array}{l}\text { ¿Tuvieron } \\
\text { certificación? }\end{array}$ & Sí & 32.6 & $\begin{array}{l}\text { En su momento la } \\
\text { necesitaron }\end{array}$ & No & 81.0 & $\begin{array}{l}\text { No han tenido o no } \\
\text { la han perdido }\end{array}$ \\
\hline ¿Por qué la dejaron? & $\begin{array}{l}\text { Ya no la } \\
\text { pide su } \\
\text { mercado }\end{array}$ & 9.3 & $\begin{array}{l}\text { No le da importancia } \\
\text { el comprador }\end{array}$ & $\begin{array}{l}\text { No hay café } \\
\text { orgánico }\end{array}$ & 14.3 & $\begin{array}{c}\text { No hay producción } \\
\text { en el país }\end{array}$ \\
\hline ¿Qué aportó? & Aprendizaje & 9.3 & $\begin{array}{l}\text { Buenas prácticas que } \\
\text { aún se aplican }\end{array}$ & Aprendizaje & 19.0 & $\begin{array}{l}\text { Buenas prácticas } \\
\text { que aún se aplican }\end{array}$ \\
\hline
\end{tabular}

Fuente: Elaboración propia. 
Para la estrategia de valor agregado a través del proceso de gestión de calidad en la selección del café se analizaron los siguientes métodos: selección en cosecha, selección por flotes, seleccionadora horizontal repasadora, seleccionadora desimétrica, selección por tamaño en verde en zarandas, selección por color, selección manual, selección por catación en taza y granulométrica, sin embargo, solo se presenta la respuesta con el porcentaje más alto de acuerdo con los Beneficios que lo aplican. En Costa Rica utilizan todos los procesos para la gestión de calidad en la selección del café porque les facilita la comercialización, les otorga mejores ingresos a los productores y obtiene una mejor calidad en taza. En México la gestión de calidad es utilizada para definir el producto de acuerdo al mercado en que se vende. Aplicar los procesos de gestión de calidad a una selección especial en microlotes es la tendencia en ambos países (Cuadro 3).

Cuadro 3.

Análisis de la estrategia de gestión de calidad

\begin{tabular}{|c|c|c|c|c|c|c|}
\hline Preguntas & Costa Rica & Porcentaje & ¿Por qué razón? & México & Porcentaje & ¿Por qué razón? \\
\hline $\begin{array}{l}\text { ¿Selecciona en } \\
\text { cosecha? }\end{array}$ & Sí & 100 & $\begin{array}{c}\text { Solo se acepta ma- } \\
\text { duro }\end{array}$ & $\begin{array}{c}\text { Se separa por } \\
\text { calidades }\end{array}$ & 57.1 & $\begin{array}{c}\text { Grado de madurez, } \\
\text { enfermedades y } \\
\text { defectos }\end{array}$ \\
\hline $\begin{array}{l}\text { ¿Qué método de } \\
\text { selección utiliza } \\
\text { más? }\end{array}$ & $\begin{array}{c}\text { Despulpador } \\
\text { de cilindro } \\
\text { horizontal }\end{array}$ & 74.4 & $\begin{array}{c}\text { Separa los granos } \\
\text { maduros }\end{array}$ & $\begin{array}{l}\text { Densimétrica } \\
\text { y por tamaño }\end{array}$ & 100 & $\begin{array}{l}\text { Se separa para dife- } \\
\text { rentes mercados }\end{array}$ \\
\hline $\begin{array}{l}\text { ¿Cuál requiere } \\
\text { mayor grado de } \\
\text { especialización? }\end{array}$ & Ninguna & 53.5 & $\begin{array}{l}\text { Son equipos fáciles } \\
\text { de usar }\end{array}$ & Por color & 42.9 & $\begin{array}{l}\text { Por el tipo de } \\
\text { equipo }\end{array}$ \\
\hline $\begin{array}{l}\text { ¿Cuál facilita la } \\
\text { comercialización? }\end{array}$ & $\begin{array}{l}\text { Todos los } \\
\text { métodos }\end{array}$ & 44.2 & $\begin{array}{l}\text { Obtienes el mejor } \\
\text { café }\end{array}$ & Por color & 61.9 & $\begin{array}{c}\text { Define el mercado } \\
\text { al que va }\end{array}$ \\
\hline $\begin{array}{l}\text { ¿Utiliza métodos de } \\
\text { selección especial? }\end{array}$ & Microlotes & 48.8 & $\begin{array}{l}\text { Se cuida más la } \\
\text { calidad }\end{array}$ & Microlotes & 38.1 & $\begin{array}{l}\text { Van con la tenden- } \\
\text { cia mundial }\end{array}$ \\
\hline $\begin{array}{l}\text { ¿Cuál otorga } \\
\text { mejores ingresos a } \\
\text { productores? }\end{array}$ & $\begin{array}{l}\text { Todos los } \\
\text { métodos }\end{array}$ & 30.2 & $\begin{array}{l}\text { Les pagan mejor sus } \\
\text { clientes }\end{array}$ & $100 \%$ maduro & 66.7 & $\begin{array}{l}\text { Les pagan mejor a } \\
\text { los productores }\end{array}$ \\
\hline $\begin{array}{l}\text { ¿Cuál mejora la } \\
\text { calidad en taza? }\end{array}$ & $\begin{array}{l}\text { Todos los } \\
\text { métodos }\end{array}$ & 34.9 & $\begin{array}{l}\text { Desde la cosecha se } \\
\text { selecciona el mejor } \\
\text { café }\end{array}$ & $\begin{array}{l}\text { Selección en } \\
\text { cosecha }\end{array}$ & 33.3 & $\begin{array}{l}\text { Es la parte más } \\
\text { importante }\end{array}$ \\
\hline $\begin{array}{l}\text { ¿Cuál es el método } \\
\text { de selección que les } \\
\text { genera mejor rela- } \\
\text { ción costo-utilidad? }\end{array}$ & Por color & 23.3 & $\begin{array}{l}\text { Genera mayor uti- } \\
\text { lidad }\end{array}$ & $\begin{array}{l}\text { Todos los } \\
\text { métodos }\end{array}$ & 47.6 & $\begin{array}{c}\text { Generan mayor } \\
\text { utilidad }\end{array}$ \\
\hline $\begin{array}{l}\text { ¿Utiliza otras } \\
\text { estrategias de valor } \\
\text { agregado? }\end{array}$ & $\begin{array}{l}\text { Prácticas } \\
\text { ecológicas }\end{array}$ & 51.2 & $\begin{array}{l}\text { Es importante cui- } \\
\text { dar el ambiente }\end{array}$ & $\begin{array}{l}\text { Estar certifi- } \\
\text { cados }\end{array}$ & 47.6 & Los diferencia \\
\hline
\end{tabular}

Fuente: Elaboración propia. 
De acuerdo a los resultados encontrados en el Cuadro 2, se realizaron diferentes correlaciones para encontrar el porqué de utilizar la estrategia de certificación. En el caso de Costa Rica, se debe a que existe una correlación entre contar con certificaciones y la capacidad instalada (Pearson de .457 $\mathrm{P}<.05$ ), esto indica que los Beneficios que benefician café certificado lo hacen por volumen y que el comprador al que va destinado pide esos volúmenes con certificaciones. En el caso de México, se encontró una correlación entre contar con certificaciones y obtener mejores ingresos (Pearson de $.693 \mathrm{P}<.05$ ), lo cual indica que son utilizadas -como se indicó en el Cuadro 2 - para asegurar y mejorar un precio. Esto destaca que las certificaciones cumplen diferentes finalidades para cada país.

Los gráficos de dispersión entre el índice de grado de integración en la cadena y el índice de gestión de calidad para ambos países muestran que, tanto en Costa Rica como en México, a mayor gestión de la calidad existe mayor integración en la cadena a través de la selección. En México, adicionalmente se encontró un índice de gestión de la calidad y de integración en la cadena mayor respecto de Costa Rica (figura 2).

\section{Costa Rica}

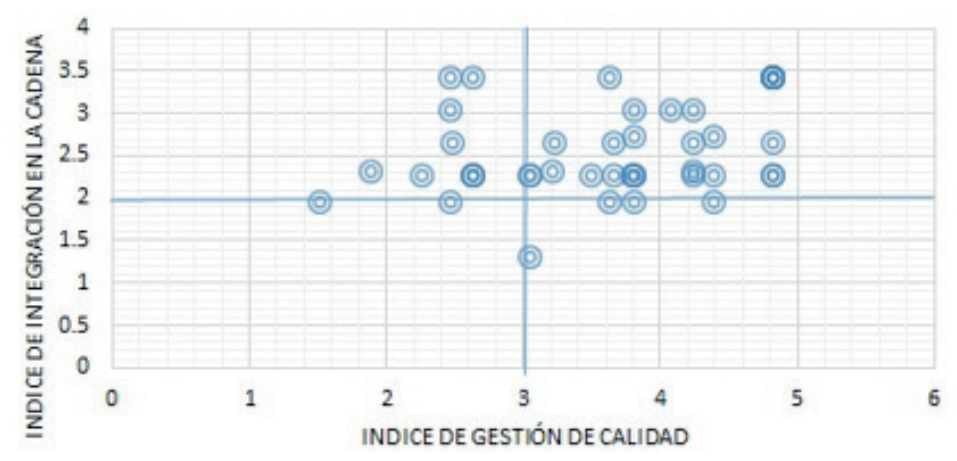

México

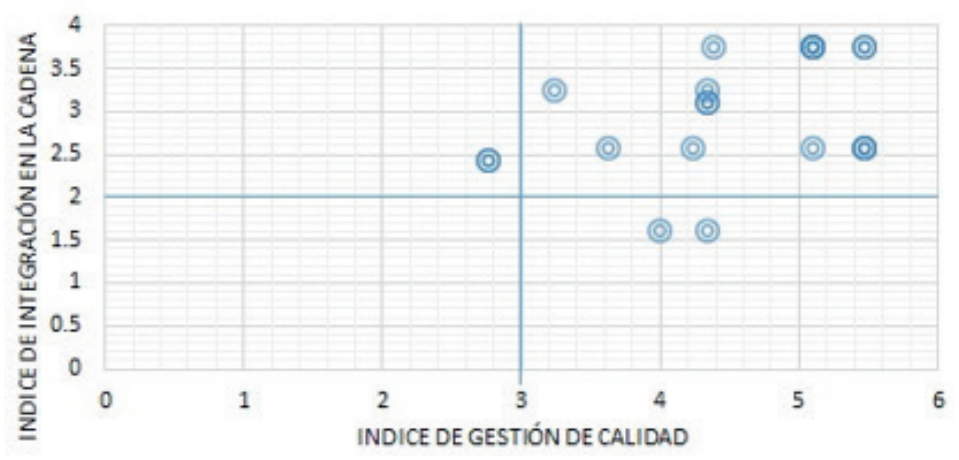

Figura 2. Índices de integración en la cadena y gestión de la calidad para Costa Rica y México 


\section{Discusión}

De los resultados encontrados en el Cuadro 1 sobresale que en Costa Rica y México, en las zonas estudiadas, la figura legal de asociación o sociedad predomina, por lo que se crean empresas particulares y se han dejado de lado la empresas formadas por unión de productores o bien las cooperativas de productores, a pesar de que el total de las cooperativas entrevistadas benefician mayor volumen de café que el total de las asociaciones.

La tendencia en Costa Rica fue ingresar a mercados especiales en micro lotes (Cuadro 3 ), pero en lugar de continuar participando en el esquema de cooperativa iniciaron sus propios Beneficios, siendo esta la principal razón por la cual aumentó el número de estos y disminuyó en promedio su antigüedad. Del mismo modo, decreció el promedio de capacidad instalada y el número de entregadores, al autobeneficiar su café o el de un menor número de integrantes, sobre todo familiares. Mientras que en México los Beneficios pertenecen a empresas grandes que comercializan y transforman por volumen de café, acopiando en promedio el triple de productores de café convencional y diferenciado respecto de Costa Rica, y apenas comenzando con la tendencia de micro lotes hacia mercados especiales.

Es importante destacar que dichas tendencias de participar directamente en el segmento de cafés especiales y cooperativas, ayudando a reducir algunas de las dificultades causadas por los precios bajos en el sector cafetalero convencional (Wollni y Zeller, 2007), se han modificado para Costa Rica en esto últimos 11 años: se sigue participando en el segmento de cafés especiales pero ahora no solamente en las cooperativas.

El café que se beneficia (transforma) en mayor porcentaje en Costa Rica es de tipo convencional, esto quiere decir que no es diferenciado como el orgánico; sin embargo, esto no lo limita a ser comercializado en mercados de especialidad. Por su parte, en México los Beneficios se dedican en mayor porcentaje a transformar café mixto, es decir tanto café convencional como diferenciado (orgánico).

El hecho de que la variedad que más se cultiva en Costa Rica es el Caturra coincide con el resultado del proceso de cambio de las variedades de café de porte bajo que les permitió la expansión de la producción en laderas (López y Picado, 2012).

En la Figura 1 encontramos que más de la mitad de los beneficios en México comienzan su participación en la cadena a partir de la compra de café en cereza, para su transformación en el beneficio húmedo. Los productores se limitan a estar en el eslabón de la finca ya que desde hace más de 25 años no están integrados en la cadena de transformación (Hoffmann, 1992).

Lo anterior es diferente en Costa Rica donde los Beneficios están coordinados desde la finca porque los productores de café forman parte de estos, no venden su café al Beneficio sino que lo entregan y son participes de las utilidades hasta la exportación, regulados por el ICAFE (Reglamento a la ley sobre el régimen de relación entre productores, beneficiadores y exportadores de café, 2016), como en el caso de las cooperativas y de las empresas o asociaciones 
privadas, que también están integrados en el primer eslabón por ser ellos mismos los productores o dueños de las fincas.

En Costa Rica solo el $2 \%$ de los Beneficios de café entrevistados no exporta (Figura 1), mientras en México esta cifra es de $19 \%$. Si tomamos en cuenta que el café exportado es pagado en dólares, México tan solo por el cambio de divisa sin tomar en cuenta el volumen, estaría teniendo menores ingresos por la venta del café no exportado.

Los resultados del Cuadro 2 nos muestran el impacto de la estrategia de certificación para agregación de valor e integración en la cadena. En Costa Rica las certificaciones han perdido el interés por parte de los Beneficios, si bien en su momento les dieron buenas prácticas para el manejo y control del proceso de transformación, en la actualidad, de acuerdo con la opinión de los Beneficios encuestados, no ofrecen dificultad ni se requiere especialización para implementarlas, ya que no les brindan ganancias frente a los costos (Lyngbaek et al., 1999; Porras et al., 2006).

Para Costa Rica solo el 41.9 \% de los Beneficios entrevistados cuenta con certificaciones, este porcentaje está compuesto principalmente por Rainforest Alliance con el $25.6 \%$, C.A.F.E. Practices con el 16.3 \%, Fair Trade con $11.6 \%$ y Carbono Neutro con el 7 \%, el resto de las certificaciones encontradas representan menos del 4.7 \% y la única razón para tenerlas es porque siguen facilitándoles el proceso de comercialización por volumen, debido a que sus compradores extranjeros así lo piden, pensando que sus clientes finales buscan el cuidado del medio ambiente y en esto coinciden los Beneficios. Sin embargo, se ha demostrado que la cadena de café es amigable con el medio ambiente y no existe impacto de los estándares de las certificaciones, excepto en los componentes del sistema que generan la huella de carbono (Segura y Andrade, 2012).

Para México, en cambio, el impacto de las certificaciones es diferente, primero porque el $66.7 \%$ cuentan con certificaciones, ya que al $81 \%$ de los Beneficios que exportan sus compradores le piden dichas certificaciones, sobre todo un café diferenciado como es el orgánico certificado. Segundo, en México no existe organismo que regule los precios del café y mida los volúmenes en las zonas cafetaleras para determinar rendimientos (como el ICAFE en Costa Rica), por ello se recurre a las certificaciones para fijar un precio, como es Fair Trade -aunado a Orgánico-, y desarrollar ventajas competitivas (Escamilla et al., 2005).

Por último y más importante, en México, en el estado de Veracruz, los productores están integrados hasta el primer eslabón de la cadena del café, así que es a través de las certificaciones como pueden generar un valor agregado a su producto y organizarse con el Beneficio, para participar de los precios/ingresos obtenidos. Las certificaciones en gran medida aseguran que los productores reciban un premio por su café, si los precios del convencional son inferiores (Garza, 2014); y basados en principios como los de Fair Trade pueden establecer proyectos de desarrollo económicos y sociales (Otero, 2006). Esto es diferente en Costa Rica, donde el $48.8 \%$ de los Beneficios aseguran que el precio de las certificaciones ya han sido superados por los precios que se pagan por cafés especiales y microlotes dirigidos principalmente a mercados asiáticos. 
En Costa Rica se aplican todos los métodos de selección para la gestión de calidad (Cuadro 3), con la finalidad de obtener mejores ingresos, mejorar la calidad de su taza y facilitar su comercialización. La parte importante de la selección inicia desde la cosecha, al recolectar solo café maduro, y una vez en el Beneficio retirar con el despulpador de cilindro horizontal los posibles cafés inmaduros que hayan quedado (Puerta, 2000b). De acuerdo con la ley 2762, el café que se recibe en los Beneficios no puede exceder del $2 \%$ de café inmaduro.

En México solo el 42.9 \% de los beneficios recolecta o compra solo maduro, lo cual hace completamente la diferencia en el resto de gestión de calidad a través de la selección. Se tiene café con distintas calidades de acuerdo al grado de madurez, defectos y enfermedades, por lo que el proceso de selección es utilizado con la finalidad de gestionar la calidad para determinar el producto de acuerdo al mercado en que va a ser comercializado. A pesar de ello, los Beneficios concluyen que el recolectar café solo maduro beneficia a la calidad en taza, pero que eso mejora los ingresos para los productores ya que se les paga mejor el café puesto que tiene más volumen y peso (Marín et al., 2003).

Otra estrategia de agregación de valor para los Beneficios en Costa Rica es que la cadena de café es amigable con el medio ambiente con prácticas ecológicas y sustentables sin necesidad de estar certificados, mientras que para México las certificaciones son su estrategia de agregación de valor.

La correlación de Pearson encontrada en Costa Rica demuestra que las certificaciones están relacionadas con la capacidad instalada, esto significa que el café que se comercializa bajo estos sellos es café que se vende por volumen y las certificaciones que se han perdido es porque ya no hay suficiente producción de café orgánico. En cuanto a las certificaciones como A.A.A., Buenas Prácticas Agrícolas, Woman Care, Asociación de cafés finos, UTZ e ISO, que solo tienen 2 o 1 Beneficio, las poseen porque va de acuerdo a lo que pide su comprador. Este hallazgo coincide con que las certificaciones son utilizadas de acuerdo a su estrategia comercial y global (Faure y Le Coq, 2009).

La correlación de Pearson entre las certificaciones y su relación con mejores ingresos para los actores que integran la cadena de valor en México, coincide con lo encontrado por Bartra et al. (2002), debido a que el café convencional no es sostenible. Al comercializar café convencional generalmente se tiene un precio más bajo en el mercado respecto del orgánico y se pone en riesgo la rentabilidad, tanto para los productores como para los Beneficios como un todo.

En ambos países se demuestra que en los Beneficios, a mayor gestión de la calidad, están más integrados en la cadena de valor (figura 2). Este resultado encontrado en los Beneficios entrevistados en ambos países, surge porque están buscando escalonar en la cadena hasta la exportación del café, para llegar a mercados especiales que paguen mejor por su producto (Wollni y Brümer, 2012). Adicionalmente, en Costa Rica la calidad y buenas prácticas que han desarrollado les permite comercializar sin necesariamente requerir por sus compradores que los Beneficios estén certificados. Ya lo explicaban López y Picado (2012), en Costa Rica se dio un 
cambio a lo largo de 30 años, en la variedad de porte bajo del café, fertilización química y elevada productividad, que conciliaron la cantidad con la calidad.

\section{Conclusiones}

La estrategia de certificación del café es útil para acceder a canales de comercialización en venta por volumen en el caso de Costa Rica; mientras que, para México, no solo le permite acceder a más canales de comercialización, sino que también le permite asegurar el precio de venta del café cuando es menor al precio que cotiza en la bolsa. Las certificaciones en ambos países aportan un aprendizaje para cuidar la calidad del café, implementar procesos de control y buenas prácticas de manejo del grano en los Beneficios.

La estrategia de selección del café en el Beneficio es clave para aumentar la calidad del mismo, permitiendo innovar en diferentes productos especializados y comercializarlo tanto en mercados tradicionales como nuevos mercados. Se concluye que un mayor grado de integración en la cadena va aunado con la implementación de la estrategia de gestión de calidad.

Es importante destacar que los procesos de certificación y gestión de la calidad están enmarcados en dinámicas locales con efectos en la organización de las cadenas globales en que participan los productores.

Para futuras investigaciones se sugiere: ampliar el tamaño de la muestra, realizarlo en otras regiones cafetaleras de México y Costa Rica, o bien con otros países productores como Colombia o Brasil. Así mismo, se sugiere administrar encuestas a consumidores de ambos países para conocer su percepción sobre la calidad, las certificaciones y el precio.

\section{Referencias}

Álvarez, C. (2008). Sistemas de certificación ambiental para la extensión tecnológica, la competitividad y el desarrollo rural. Producción + Limpia, 3(2), pp. 61-87.

Bartra, A.; Cobo, R.; Meza, M. y Paz, L. (2002). Sombra y algo más. Hacia un café sustentable mexicano. Estudio café de sombra en México. Instituto Maya, pp. 1-23.

Castillo, M. (2001). ¿El mercado del café: ahora hacia dónde? Revista Economía Colombiana y coyuntura política, 290, pp. 58-62.

Cattaneo, O.; Gerefi, G.; Miroudot, S. y Taglioni, D. (2013). Joining, Upgrading and Being Competitive in Global Value Chains: A Strategic Framework. Policy Research Working Paper, 6406, pp.1-50.

Escamilla, E.; Ruiz, O.; Díaz, G.; Landeros, C.; Platas, D. E.; Zamarripa, A. y González, V. A. (2005). El agroecosistema de café orgánico en México. Manejo Integrado de Plagas y Agroecología, 76, pp. 5-16. 
Faure, G. y Le Coq, J. F. (2009). Estrategias de las cooperativas cafetaleras frente a los sellos ambientales en Costa Rica. Versión No.1 Informe en el marco del proyecto CAFNET. CIRAD, pp.1-65.

García, R. y Olaya, É. (2006). Caracterización de las cadenas de valor y abastecimiento del sector agroindustrial del café. Cuad. Adm. Bogotá (Colombia), 19(31), pp. 197-217.

Garza, A. (2014). El impacto del Comercio Justo en el desarrollo de los productores de café. Estudios sociales, 43, pp. 272-293.

Gereffi, G. (2001). Las cadenas productivas como marco analítico para la globalización. Problemas del Desarrollo, 32(125), pp. 9-37.

Hoffmann, O. (1992). Renovación de los actores sociales en el campo: un ejemplo en el sector cafetalero en Veracruz. Estudios Sociológicos, 10(30), pp. 523-554.

Instituto del Café de Costa Rica. (2016). Reglamento a la ley sobre el régimen de relación entre productores, beneficiadores y exportadores de café. Recuperado de http://www.icafe.cr/ icafe/publicaciones/leyes-y-reglamentos/.

Instituto del Café de Costa Rica. (2017). Mills, Exporters and Roasters Guide. Recuperado de http://www.icafe.cr/wp-content/uploads/directorios sector.

Instituto del Café de Costa Rica. (2018). Estructura del sector. Recuperado de http://www.icafe.cr/ nuestro-cafelestructura-del-sectorl.

International Business Machines. (2010). IBM SPSS Statistics. Versión 19. Recuperado de https:// ibm-spss-statistics.softonic.com/.

Jaramillo, C. y Riveros, H. (2013). Catálogo de iniciativas públicas para favorecer el desarrollo de los agronegocios y la agregación de valor en países referentes de América Latina. Instituto Interamericano de Cooperación para la Agricultura.

Kosacoff, B. y López, A. (2008). América Latina y las Cadenas Globales de Valor: debilidades y potencialidades. Revista de Globalización, Competitividad y Gobernabilidad, 2(1), pp. $18-32$.

López, M. y Picado, W. (2012). Plantas, fertilizantes y transición energética en la caficultura contemporánea de Costa Rica. Bases para una discusión. Revista Historia, 65-66, pp. 17-51.

Lyngbaek, A.; Muschler, R. y Sinclair, F. (1999). Productividad, mano de obra, costos variables en fincas cafetaleras orgánicas y convencionales de Costa Rica. Agroforesteria en las Américas, 6(23), pp. 24-26. 
Marín, S. M.; Arcila, J.; Montoya, E. C. y Oliveros, C. E. (2003). Relación entre el estado de madurez del fruto del café y las características de beneficio, rendimiento y calidad de la bebida. Cenicafé, 54(4), pp. 297-315.

Montoya, W. y Montoya, J. (2015). Factores determinantes para la creación y adición de valor al café en el municipio de Dosquebradas (Risaralda, Colombia). Gestión y Región, 19, pp. $55-71$.

Oliveros, C. E.; Pabón, J. P.; Montoya, E. C.; Ramírez, C. A. y Sanz, J. R. (2010). Separación de frutos de café verdes por medios mecánicos. Cenicafé, 61(3), pp. 260-269.

Otero AI. (2006). El comercio justo como innovación social y económica: el caso de México. Observatoire des Amériques, 35.

Pelupessy, W. (2001). El Enfoque de la cadena global de mercancías como herramienta analítica en las economías en vías de desarrollo. Economía y Sociedad 6(15), pp. 111-120.

Pérez, P. y Echánove, F. (2005). Cadenas globales y café en México. Cuadernos Geográficos, 38(2006-1), pp. 69-86.

Peters, G. (2004). Exportadores y consignatarios del café costarricense a finales del siglo XIX. Revista Historia, 49, pp. 59-109.

Porras, C.; Soto, G.; Melo, E.; Casanoves, F. y Tapia, A. (2006). Comparación de manejos orgánico y convencional de café dentro del Corredor Biológico Turrialba-Jiménez, Costa Rica. VII Congreso SEAE Zaragoza, 149.

Porter, M. (1990). The Competitive Advantage of Nations. New York: Free Press.

Puerta. G. I. (2000a). Influencia de los granos de café cosechados verdes, en la calidad física y organoléptica de la bebida. Cenicafé, 51(2), pp. 136-150.

Puerta GI. (2000b). Beneficie correctamente su café y conserve la calidad de la bebida. Avances Técnicos Cenicafé, 276, pp. 1-8

Segura, M. y Andrade, H. (2012). Huella de carbono en cadenas productivas de café (Coffea arabica L.) con diferentes estándares de certificación en Costa Rica. Luna Azul, 35, pp. 60-77.

Servicio Nacional de Sanidad Inocuidad y Calidad Agroalimentaria. (2018). Directorio de Beneficiadoras, Centros de acopio e Industrializadoras de Café. Recuperado de https://www. gob.mx/cms/uploads/attachment/file/328439/Centros de acopio de caf 21052018.pdf.

Soto, C. y Jiménez, R. (1995). Secuencia de operaciones en la preparación de café oro y su influencia en el desempeño de los clasificadores electrónicos. Agronomía Costarricense, 19(1), pp. 7-13. 
Specialty Coffee Association of America. (2018). SCAA Coffee Standards. Recuperado de https:// sca.coffee/research/coffee-standards?page=resources $\& d=$ coffee-standards

Wollni, M. y Brümer, B. (2012). Productive efficiency of specialty and conventional coffee farmers in Costa Rica: Accounting for technological heterogeneity and self-selection. Food Policy, 37, pp. 67-76.

Wollni, M. y Zeller, M. (2007). Do farmers benefit from participating in specialty markets and cooperatives? The case of coffee marketing in Costa Rica. Agricultural Economics, 37, pp. 243-248. 